\title{
Theoretical and Experimental Investigations on 20 Inches Threaded Casing Connections Failure under Field Conditions
}

\author{
Dragos Gabriel Zisopol \\ Mechanical Engineering Department \\ Petroleum-Gas University of Ploiesti \\ Ploiesti, Romania \\ zisopol@zisopol.ro
}

Marius Badicioiu

Mechanical Engineering Department

Petroleum-Gas University of Ploiesti

Ploiesti, Romania

mbadicioiu@upg-ploiesti.ro

\author{
Mihaela Madalina Caltaru \\ Mechanical Engineering Department \\ Petroleum-Gas University of Ploiesti \\ Ploiesti, Romania \\ miki@upg-ploiesti.ro \\ Mihail Minescu \\ Mechanical Engineering Department \\ Petroleum-Gas University of Ploiesti \\ Ploiesti, Romania \\ mminescu@upg-ploiesti.ro
}

\begin{abstract}
This paper brings forward the results of theoretical and experimental investigations performed to determine the causes that led to the failure of $\mathbf{2 0}$ inches threaded casing connections during the tubing of the Lupşa Sat No. 1 oil well, Romania. The failure occurred due to the breakout of the threaded casing connections assembled in the factory. In order to establish the main causes of failure, theoretical investigations were taken into consideration to highlight the influence of the thread element errors on the correct make-up casing pin-coupling (box) conditions and to the axial tensile strength of the threaded casing connection. In addition, experimental investigations were performed on the failure casing connections, consisted of measuring the dimensional characteristics of the thread elements to determine the performance and monitor the technical condition of the tubular material used in the petroleum industry.
\end{abstract}

Keywords-threaded casing connections; failure; investigation; expertise

\section{INTRODUCTION}

Well casing is necessary after the drilling of the borehole in order to consolidate the well, to protect the borehole from falling, to protect the fresh water aquifers by preventing the drilling fluids used or oil to seep into the underground water reservoirs, and to facilitate the execution of work operations (drilling or exploitation). For this purpose, surface casing is used, consisting of casings assembled together by threaded casing connections (Figure 1). The casings used for well casing are steel pipes with both ends threaded (casing pin). The casing manufacturer, according to references standards, assembles in the factory the coupling (box) at one casing threaded end (threaded casing connections-factory assembled), and during the well casing, the other threaded end of the casing is assembled in the operation field (threaded casing connections- borehole assembled), by makeup to the coupling (box) of another casing (Figure 2). Deviations of shape and dimensions of the threaded casing connection can conduct to failure, often manifested by losing the sealing capacity and, more seriously, by jump-out or even by fracture of the thread connection [1]. Therefore, the international standards in the petroleum field predict the dimensions of the threaded casing connections used for well casing to fit within in a very restrictive tolerance field. Any deviation from the prescribed limit leads to pulling out the use of the respective connection. In order to prevent any incident due to non-compliance with the shape and dimensions, the international test standards of the casing connections impose a rigorous inspection of the threaded casing connection prior to their use. The statistical dates reveal the fact that $86 \%$ of the surface casing failure occurs due to the threaded casing connections [2].

The present paper brings forward theoretical and experimental investigations performed to determine the causes that led to an accident during the construction of the Lupşa Sat No. 1 oil well, Romania. The accident occurred during the well casing, at a depth of $262.88 \mathrm{~m}$, and consisted of the failure of casing connections (Figure 1) by breakout of the threaded factory assembled casing connections. The breakout occurred during the stationary period at a hook load value of 42 tons. This load value shows that the weight of surface casing in the drilling fluid, under the failure area, was inferior to the tensile strength of the threaded casing connection, properly made-up by the manufacturer, which does not justify its breakout.

There is no information available regarding the failure of the surface casing in the operation field, occurring due to the breakout of the threaded factory assembled casing connection. In order to establish the main causes that led to the breakout of 
the threaded casing connections, a theoretical study according to standardized information to reveal the influence of the threaded elements errors on the makeup conditions of casing connection was performed along with an experimental study necessary to establish precisely and rigorously the failure causes. The failure analysis performed in this work can be proved useful for specialists in the petroleum field, to prevent the occurrence of such event by taking into consideration the influence of the thread elements errors to the correct make-up threaded casing connection. The current investigation brings forward and justifies the importance of correct makeup threaded casing connection in the factory to avoid possible failures in the operation field.

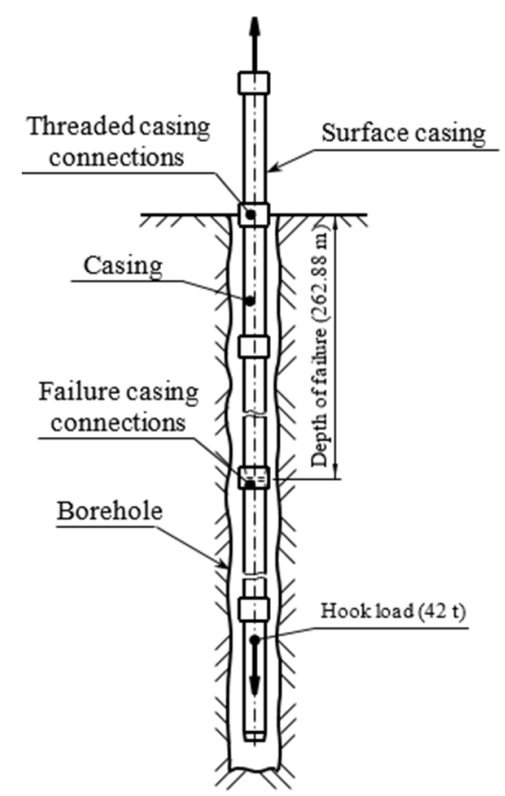

Fig. 1. Schematically representation of the surface casing.

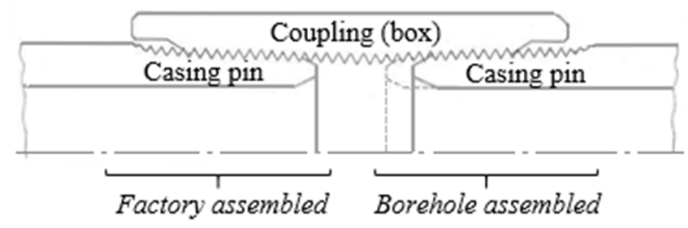

Fig. 2. Threaded casing connections.

\section{THEORETICAL INVESTIGATIONS TO THE THREAD ELEMENT ERROR INFLUENCES}

The main target of the theoretical study was to investigate, according to reference standards and specialized literature, the influences of the thread element errors to the correct make-up casing pin-coupling (box) conditions and to the axial tensile strength of the threaded connection of the casing connection. The tensile strength of the threaded casing connection represents the lowest value of the following: the fracture load in the section next to the last perfect thread, the force corresponding to the shearing of the thread, and the jump-out force in the thread. Because the fracture load (corresponding to the mechanical characteristics) is much higher than the value at which the breakout of the thread connection occurred, and the shearing of the thread does not occur practically at the round API thread, the only failure form considered possible is the jump-out of the thread connection. The specialized literature shows that approximately $91 \%$ of the failure casing connection occurs due to jump-out of the thread connection $[3,4]$.

The role of the make-up torque is to develop a radial contact pressure between the threads (pre-tensioning) by performing a diametral tightening due to the relative axial displacement between the coupling (box) and the casing pin. Radial pre-tensioning is achieved by mechanically applying approximately 4 rotations in addition to manual make-up and it is intended both to ensure the sealing of the thread connection and to avoid relative radial displacement of the casing pin and box threads that allow the jump-out of the thread under the action of radial component of the tensile force. The thread parameters contained in the formula for determining the jumpout force of the thread are also decisive for the makeup torque value [2], and it was found that the experimentally determined makeup torque (in $\mathrm{ft.lb}$.) to achieve a quality threaded casing connections represents $1 \%$ from the jump-out force value of the thread (in lb.) [2]. In the specialized literature, this predication is the base for establishing the recommended values for the make-up torque [2], and also highlights the close correlation between the make-up torque and the jump-out force of the thread connection. Make-up torque lower than the recommended value can lead to jump-out thread because the radial pressure between the threads is not achieved to provide the standardized value of the axial tensile force [5]. The causes of the reduction for the jump-out strength of the thread are indicated as improper make-up of the casing connection by the manufacturer and the ovality of the casing (deviation from the cylindricity) [6].

In order to make a correlation between the causes of failure and the results of laboratory investigations on threaded connections, the influence of errors (deviations) on the average diameter in the measurement plan for manual makeup was studied along with the influence of ovality to the correct makeup casing pin - coupling (box) conditions.

\section{A. Effect of the Thread Pitch Diameter Deviations}

In the year that this investigation took place, the pitch diameter in the plane of hand-tight engagement, $E_{1}$ (Figure 3), was not provided with limit deviations in the specific standards. Under the conditions in which the pitch diameter of the box connection corresponds to the standardized value, and the pitch diameter of the pin connection is $\Delta d \mathrm{~mm}$ smaller than the standardized value, the box connection will move axially with the value $\Delta a$ beside the position that theoretically corresponds to the manually make-up connection:

$$
\Delta a=\frac{\Delta d}{k}
$$

in which $k$ is the thread taper.

At $2 \mathrm{~mm}$ reduction of the pin thread diameter, the axial displacement of the box connection, given by (1) has the value:

$$
\Delta a=\frac{2}{\frac{1}{16}}=32 \mathrm{~mm}
$$


representing an about 10 thread lead.

In fact, due to the ovality of the pin thread, the maximum diameter of the pin can be taken into account which is only $0.3 \mathrm{~mm}$ lower than the standardized value. This leads to an axial displacement of the box connection of:

$$
\Delta a=\frac{0,3}{\frac{1}{16}}=4.8 \mathrm{~mm}
$$

Therefore, 2 of the 4 recommended revolutions are consumed at casing connection make-up. This hypothesis is not realistic because, during the make-up connection, the pin connection is elastically deformed to the direction of the maximum diameter.

On the basis of these considerations, in order to avoid the improperly make-up connection, the manufacturers have established their own precision requirements for the pitch diameter in the plane of hand-tight engagement, $E_{1}$, and for ovality, [7-10], such as those specified by the Gagemaker Company [11], for the ovality tolerances of the pin and box connection: $0.060 \mathrm{in}(1.524 \mathrm{~mm})$. The study of the literature has led to the observation that the tolerances practiced globally for ovality by different companies and norms are very close or identical.

\section{B. Effect of the Ovality on the Improper Make-up Casing Connection}

The standards do not contain prescriptions regarding the tolerance of the thread's ovality or casing. Indirectly, the ovality of the casing is controlled by the tolerance to the outer and inner diameters. The usual tolerance values of $+1 \%$ (for the outside diameter) and of $-0.5 \%$ (for the inside diameter) correspond to an ovality of $1.5 \%$. The threads made by cutting present much lower deviations of ovality. The gauges are used to control the pitch diameter in the measuring plane. Determining the standoff can lead to the acceptance of an oval casing connection, but it can have a value for the pitch diameter below the specified one [10]. The ovality is reduced by elastic deformation during the make-up casing connection, but leads to additional non-uniform stresses on the circumference of the threaded connection, which overlaps with the stresses induced by the make-up torque.

At an oval casing connection, the theoretical contact of the threads for pin and box connection onto the entire circumference is achieved only by contact realized on two opposing generating lines, which correspond to the maximum diameter of the pin cone. This situation is confirmed by the galling marks on the threads next to these generating lines. In this situation, the contact of the threads only at one side of the circumference gives incorrect indications about the make-up torque and leads to a sensible reduction of the jump-out force in the thread. In API Specification 5CT/ISO 11960: 2001, it is noted that the assembly of the box connection to the casing, realized by the casing manufacturer, although sealed at the time of make-up connection, does not always maintain its sealing after transport, handling, or usage.

\section{EXPERIMENTAL INVESTIGATION TO THE THREADED CASING CONNECTIONS}

The casing connection involved in this accident, manufactured according with the API Specification 5CT/ISO 11960 and API Specification 5B, is a threaded connection for casing having an outer diameter of $20 \mathrm{in}$, material grade type $\mathrm{J} 55$, and wall thickness of $11.13 \mathrm{~mm}$, fitted with a round thread type API 8-Round (Figure 3) [7]. The box of the casing connection has an outer diameter of 21 in and a length of $230 \mathrm{~mm}$.

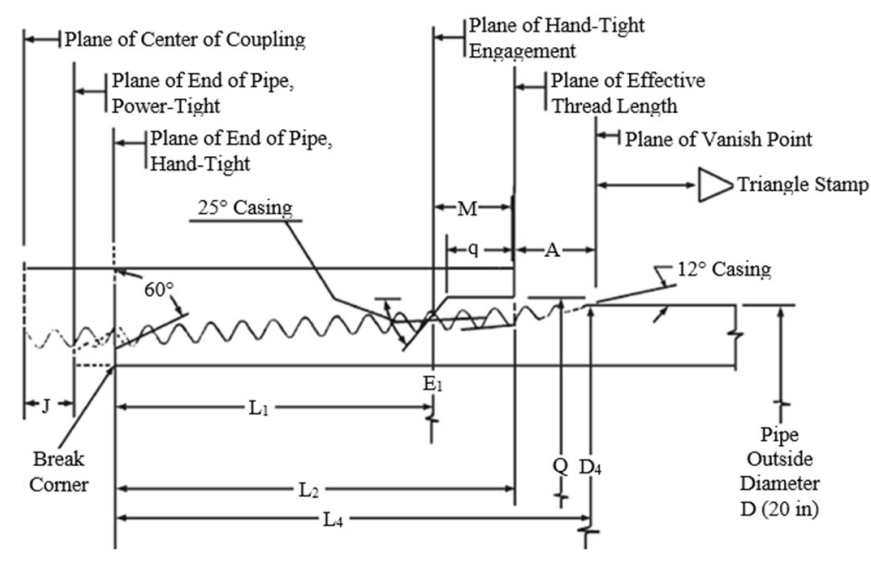

Fig. 3. Round threads casing connection.

As a result of the visual examinations it was found that there were no traces of thread deterioration to highlight the fact that the casing has been jump-out from the box, but there were only slightly traces of damage by bumping or galling. Investigation was performed in order to explain the causes of breakout of the casing connections (factory assembled). All the submitted documents for casing connections involved in the event were studied regarding the technical manufacturing conditions and the accident's occurrence conditions. Also, experimental research and analysis were performed in the laboratories of the Petroleum-Gas University of Ploiesti for determining the mechanical characteristics of the material, its chemical composition and all the elements of the pin and box casing connection were measured. In order to establish the casing material, tests were performed on specimens taken from the failed casing connection and the obtained results confirmed the fact that the material used for manufacturing correspond to grade J55, according to API Specification 5CT [12].

The dimensional characteristics of the thread elements were determined on the two elements of the casing connection (Figure 4), made available by the beneficiary. Thread element measurement was performed according to [7] using the Gagemaker verification tools and procedures (Figure 5), and instruments for thread profile verification STARRETT HF600 and ALLEN \# 3285 (Figure 6). Thus, the dimensions of the thread elements for casing connection (pin and box), provided with tolerances in the API 5B Spec standard (thread profile, thread height, thread lead, thread taper, pitch diameter and ovality, total thread length between the end of pipe to vanish point, andeffective thread length), were measured. 

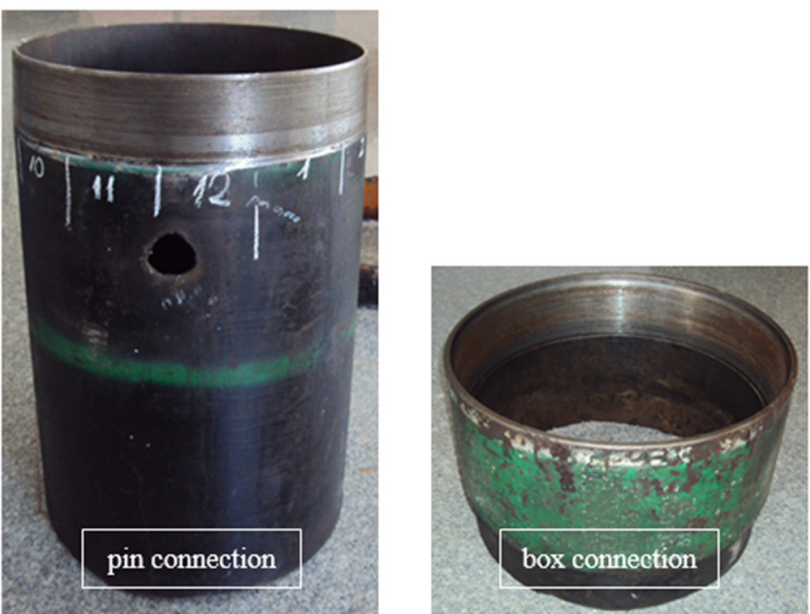

Fig. 4. Analyzed casing connection.

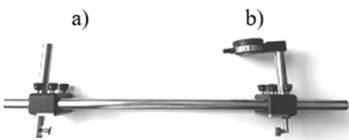

f)

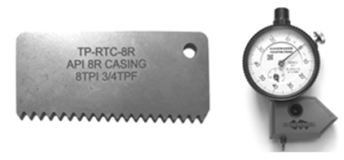

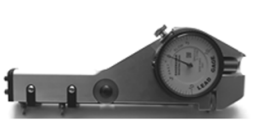

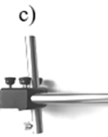

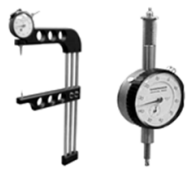

- The pin and box threads have the appropriate heights, within the tolerance specified in API Specification 5B.

- The values obtained for thread lead errors per inch, thread taper, total thread length $\mathrm{L}_{4}$, and effective thread length $\mathrm{L}_{2}$, determined for both casing connection elements (pin and box), fall within the limits specified in API Specification $5 \mathrm{~B}$.

- Verification of the pitch diameter revealed that the differences between the standardized value and the average values of the pitch diameter, determinated in the case of the box thread, are very small and fall within the range of -0.31 $\div 0.33 \mathrm{~mm}(-0.012 \div 0.013 \mathrm{in})$, and in the case of the pin thread, they have negative values, ranging in the range $-2.31 \div-0.31 \mathrm{~mm}(-0.091 \div-0.012 \mathrm{in})$, with a maximum value of $-2.7178 \mathrm{~mm}$.

- The thread ovality values determined after the box measurements were found to be within the limits recommended by the API 8 - Short round thread, but the ovality values obtained for the pin thread exceeds the recommended limits $(2.464 \mathrm{~mm}$ from the recommended maximum $1.524 \mathrm{~mm}$ ).

Figure 7 shows photographs taken during the thread geometry measurements. Taking into consideration all the theoretical analyses and experimental investigations performed on the casing connection, we proceeded to interpret the causes of the failure of the surface casing by breakout the threaded connections (factory assembled).
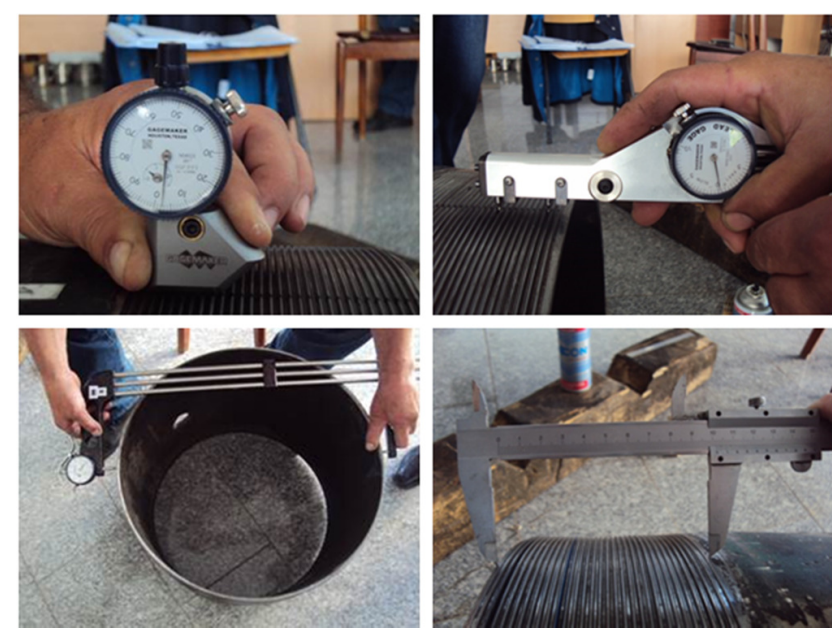

Fig. 7. Images during the performed thread geometry measurements.

So, the analysis concerning the specialized literature and the prescriptions of standards API Bul. 5C2 [13] and API Bul. $5 \mathrm{C} 3$ [14], highlights the recommended values for make-up torque and jump-out strength (tensile strength) of the thread connection type API 8 - Short Round Thread (8 thread/inch) shown in Table I, corresponding to casing having outer diameter of 20in, material grade type J55, and wall thickness of $11.13 \mathrm{~mm}$.

By comparing the tensile strength of the threaded connection $(3484 \mathrm{kN})$ with the hook load value at which the 
damage occurred $(420 \mathrm{kN})$, it was found that, even though a casing connection, like the examined one, is correctly made-up, the jump-out strength is approximately 8 times greater than the load at which the threaded connection breakout occurred. As has been shown from the measurements made on the geometric elements of the threaded connection, all thread dimensions are within the standard tolerance field, except for the pitch diameter of the pin thread and ovality. Taking into consideration the above mentioned facts, it can be concluded that the mechanized make-up box and pin connection, respecting the indication as the frontal face to be corresponding to the base of the casing triangle stamp in the plane of vanish point, does not lead to the development of the radial contact pressure between the threads taken into consideration when establishing the conditions for achieving the correct make-up connecting.

TABLE I. RECOMMENDED VALUES

\begin{tabular}{|c|c|c|c|}
\hline \multirow{2}{*}{ Make-up torque } & Minimum & $7960 \mathrm{Nm}$ & $5870 \mathrm{ft} .1 \mathrm{~b}$. \\
\cline { 2 - 4 } & Optimum & $10620 \mathrm{Nm}$ & $7830 \mathrm{ft} . \mathrm{lb}$. \\
\cline { 2 - 4 } & Maximum & $13270 \mathrm{Nm}$ & $9790 \mathrm{ft} .1 \mathrm{~b}$. \\
\hline Tensile strength & & $3483 \mathrm{kN}$ & $783000 \mathrm{lb}$. \\
\hline
\end{tabular}

As a conclusion, the probable cause of the breakout casing connection (factory assembled) is represented by make-up connection with a make-up torque value insufficient to assure the standard jump-out strength, due to the deviations to pitch diameter and ovality. Although the breakout casing connection (factory assembled) did not lead to a serious failure, the event highlights the need to pay extra attention to the threading operations and especially to the control of threaded connection and make-up conditions. Also it is recommended to perform a risk management evaluation [15].

\section{CONCLUSIONS}

In order to explain the causes of failure during the well casing of the surface casing due to the breakout threaded casing connections (factory assembled) during the field operation, theoretical and experimental investigations were performed. It was established that all thread element errors are important factors for the assurance of optimum makeup torque of the casing connections. In the case of the investigated casing connection, the deviation from the ovality led to the nonachievement of the optimal makeup torque, which allowed the breakout of the threaded connections (factory assembled) in the borehole.

\section{REFERENCES}

[1] N. Konkong, "An Investigation on the Ultimate Strength of ColdFormed Steel Bolted Connections," Engineering, Technology \& Applied Science Research, vol. 7, no. 4, pp. 1826-1832, Aug. 2017, https://doi.org/10.48084/etasr.1243.

[2] V. Ulmanu, Material tubular petrolier. Bucharest, Romania: Editura Tehnică, 1992.

[3] T. H. Hill, "What you should know about OCTG inspections," World Oil, vol. 199 , no. 5, pp. 64-68, Oct. 1984.

[4] T. H. Hill, "Tracking OCTG inspection results saves time and money," World Oil, vol. 201, no. 5, pp. 70-72, Oct. 1985.

[5] K. K. Biegler, "Conclusions Based on Laboratory Tests of Tubing and Casing Connections," presented at the SPE Annual Technical
Conference and Exhibition, Sep. 1984, https://doi.org/10.2118/13067MS.

[6] IADC Drilling Manual. Technical Toolboxes Inc., 2000.

[7] API SPEC 5B : Threading, Gauging, and Inspection of Casing, Tubing, and Line Pipe Threads. API, 2010.

[8] "Seal-lock HT Ancillary Specification." Hunting.

[9] M. L. Payne, R. E. Leturno, and C. A. Harder, "Improving operational procedures can reduce fatigue failure in 8-rd casing," Oil and Gas Journal; (United States), vol. 92, no. 48, Nov. 1994.

[10] Quality Procedures. Energy Technology Manufacturing \& Threading, LLC.

[11] TDWIN TAPER Thread Disk for Tapered Threads. HOU, USA: Gagemaker, 2011.

[12] Technical Committee ISO/TC 67/SC 5, ISO 11960:2001: Petroleum and natural gas industries - Steel pipes for use as casing or tubing for wells. 2001.

[13] Bulletin on Performance Properties of Casing, Tubing, and Drill Pipe. API, 1989.

[14] Bulletin on Formulas and Calculations for Casing, Tubing, Drill Pipe and Line Pipe Properties. API, 1989.

[15] A. Chenarani and E. A. Druzhinin, "A Quantitative Measure For Evaluating Project Uncertainty Under Variation And Risk Effects," Engineering, Technology \& Applied Science Research, vol. 7, no. 5, pp. 2083-2088, Oct. 2017, https://doi.org/10.48084/etasr.1530. 